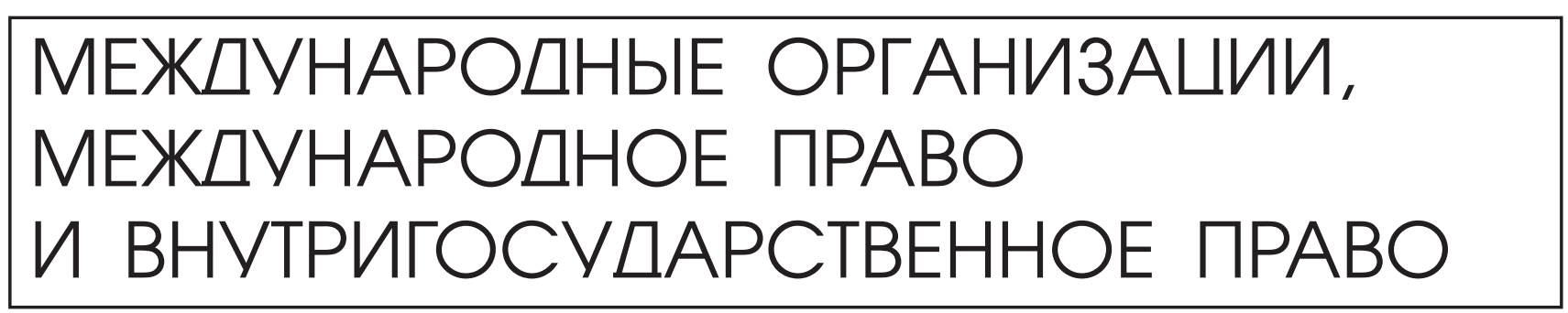

Варавенко В.E.

\title{
ТИПОВОЕ СОГЛАШЕНИЕ О ПРЕДСТАВИТЕЛЬСТВЕ МЕЖДУНАРОДНОЙ ФЕДЕРАЦИИ ИНЖЕНЕРОВ КОНСУЛЬТАНТОВ (FIDIC): ПЕРСПЕКТИВЫ ПРИМЕНЕНИЯ В УСЛОВИЯХ РОССИЙСКОЙ ПРАВОВОЙ СИСТЕМЫ
}

Аннотация. Предметом исследования являются условия Типового соглашения о представительстве (далее - Соглашение), опубликованного Международной федерацией инженеров консультантов (FIDIC) в 2013 году, а также нормы отечественного и зарубежного права, регулирующего посреднические отношения (нормы главы 52 Гражданского кодекса РФ и нормы права Англии и Уэльса, регулирующие посреднические отношения (Agency). Соглашение предназначено для оформления и регулирования посреднических отношений между инжиниринговыми, строчтельными, проектировочными компаниями и компаниями, оказывающими посреднические услуги, способствующие выходу зарубежных компаний на национальный рынок соответствуюших работ (услуг). Для решения исследовательских задач используется сравнительно-правовой метод, посредством которого анализируются условия типового соглашения и нормы национальных правопорядков. Исследование представляет собой первый аналитический отчет о содержании Типового соглашения о представительстве FIDIC 2013 г. Сделан вывод об отсутствии принципиальных юридических барьеров, препятствующих применению Соглашения российскими компаниями, желающими оказывать посреднические услуги зарубежным инжиниринговым компаниям и проектировщикам. Вместе с тем, распределение рисков между сторонами Соглашения произведено в пользу зарубежных компаний, что необходимо учитьвать, принимая решение об использовании данной договорной модели.

Ключевые слова: FIDIC, типовое соглашение, посредничество, антикоррупционнье условия, посредник, инжиниринговая компания, проектировщик, фактические полномочия, явно выраженные полномочия, подразумеваемые полномочия.

Abstract: The subject of this research is the terms of the Model Representative Agreement (furtherAgreement) of the International Federation of Consulting Engineers (FIDIC) of 2013, as well as the norms of Russian and foreign law that regulates the agency relations (norms of Chapter 52 of the Civil Code of the Russian Federation, and legal norms of England and Wales, which regulate agency relations). The agreement is meant to structure and regulate agency relations between the engineering, construction, and project management companies, as well as companies providing intermediary services, helping foreign countries enter the national market of corresponding services. This research represents a first analytical report on the content of the Model Representative Agreement of FIDIC of 2013. The author concludes that there is lack of principal juridical obstacles that would prevent appli- 
cation of the Agreement by Russian companies seeking to provide intermediary services to international engineering companies and project planners. In addition to that, the distribution of risk between the sides of the Agreement is on the side of the foreign companies, which needs to be considered in decision making on the use of this model of agreement.

Keywords: Actual authority, project manager, engineering company, agent, anticorruption clause, intermediary, model agreement, FIDIC, express authority, implied authority.

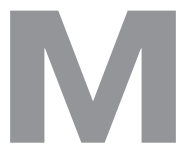

еждународная федерация инженеров-консультантов (FIDIC) опубликовала в 2013 году новое типовое соглашение, призванное регулировать отношения между инженерами-консультантами и посредниками, содействующими консультантам в их деятельности: Типовое соглашение о представительстве (Model Representative Agreement) или Пурпурная книга (Purple Book) 2013 г. (далее - Пурпурная книга, Соглашение). Разработчики Соглашения преследовали две цели: (1) создание юридической основы оказания посреднических услуг, необходимых инжиниринговым компаниям и проектировщикам для участия в инвестиционно-строительных проектах за рубежом, и (2) создание механизмов противодействия коррупционным практикам, существующим в указанной сфере.

Зарубежные компании, осуществляющие деятельность в области проектирования, инжиниринга и проджект-менеджмента, желающие участвовать в проектах, реализуемых за пределами их стран, заинтересованы в содействии квалифицированного посредника, который способен оказать услуги, как предшествующие вхождению консультанта в проект, так и сопровождающие его участие в проекте. Вместе с тем, подобная посредническая деятельность является питательной средой для коррупционных злоупотреблений, таких как подкуп членов конкурсных комиссий, принимающих решения об отборе участников проекта; подкуп должностных лиц для 160 получения разрешений, допусков, положительных заключений и т.п. Опубликование Пурпурной книги является ответом на указанные потребности и вызовы практики.

Целью данной работы является определение перспектив применения Пурпурной книги российскими компаниями, желающими оказывать зарубежным консультантам посреднические услуги на территории России. Для достижения указанной цели необходимо решить ряд исследовательских задач, в том числе определить соотношение Пурпурной книги с договорными моделями, предусмотренными российским гражданским законодательством и предназначенными для урегулирования отношений представительства, а также выявить степень сбалансированности условий Соглашения в части распределения рисков между сторонами.

Предметом исследования являются, прежде всего, Общие условия Пурпурной книги: раздел типового соглашения содержащий стандартные условия, которые применяются по умолчанию, а также нормы российского и зарубежного права, предназначенные для регулирования отношений посредничества.

\section{1. Пурпурная книга как юридическая основа оказания посреднических услуг.}

Российскому законодательству известны три договорные модели, используемые для организации отношений посредничества: договор поручения (глава 
49 ГК РФ), договор комиссии (главы 51 ГК РФ) и агентский договор (глава 52 ГК РФ). Указанные договорные модели разграничиваются на основе следующих критериев: (1) какой субъект права может выступать в роли посредника (физическое лицо, юридическое лицо, любые субъекты права); (2) каковы функции посредника (совершение исключительно юридических действий или как юридических, так и фактических действий); (3) в каком качестве действует посредник (от своего имени или от имени доверителя). Проанализируем условия Пурпурной книги в свете указанных критериев.

Согласно пдп. 1.8 Общих условий Пурпурной книги «Представитель» (Representative) определяется как «сторона, указанная в Соглашении, привлеченная Консультантом в качестве физического лица или компании для оказания посреднических услуг» $[2$, с. 1]. Таким образом, в роли посредника по Соглашению могут выступать как физические, так и юридические лица.

В соответствии с пдп. 3.1 Общих условий Пурпурной книги посредник «обязан по требованию Консультанта оказывать любые разумно запрашиваемые посреднические услуги, указанные в Приложении № 1 к Особым условиям» [2, с. 2]. Перечень услуг, приведенный в Приложении № 1, свидетельствует о том, что в объем обязанностей посредника входит совершение различных по своей природе действий в интересах доверителя: регистрация консультанта в компетентных органах страны места оказания посреднических услуг (пункт А9), получение для консультанта разрешений, допусков, виз, необходимых консультанту или его сотрудникам (пункты А6 и В1), информирование консуль- танта об общих условиях и тенденциях (в экономике, политике, праве), которые могут повлиять на интересы консультанта связанные с участием в проекте (пункты A8 и B8) [2, с. “b” - “c”]. Таким образом, Пурпурная книга предполагает совершение посредником как юридических, так и фактических действий в интересах доверителей.

Анализ перечня обязанностей посредника, закрепленного в Приложении № 1 к Особым условиям Пурпурной книги, указывает на то, что посредник, выполняя поручения доверителя, может действовать как от имени доверителя, так и от своего имени. Например, посредник обязан «от имени Консультанта устанавливать и поддерживать связи с соответствующими правительственными и деловыми кругами, для своевременного и надлежащего уведомления Консультанта о доступных возможностях...» (пункт А 3) [2, с. “b”]. В то же время, обязанности по организации оказания гостиничных и транспортных услуг для сотрудников консультанта, закупок материально-технических средств, необходимых для участия в проекте, предусмотренные в пунктах В2 и В3 Приложения № 1 [2, с. “с”], свидетельствуют о том, что ряд действий посредник может совершать от своего имени.

Признаки Пурпурной книги, выявленные в ходе сравнительного анализа, свидетельствуют в пользу квалификации данного типового соглашения как агентского договора, предусмотренного отечественным гражданским законодательством, а отношения между посредником и зарубежной компанией - отношениями агентирования.

Вместе с тем, квалификация отношений посредника и доверителя как агентских 
наталкивается на оговорку, закрепленную в пдп. 4.4 Общих условий Пурпурной книги: «Представитель, ни при каких обстоятельствах, кроме случаев, когда он надлежащим образом уполномочен ответственным сотрудником Консультанта, не должен: рассматриваться в качестве агента Консультанта; иметь какие-либо права или полномочия по созданию обязательств от имени Консультанта; заключать договоры и соглашения от имени и в интересах Консультанта; или создавать обязательства для Консультанта каким-либо иным образом» [2, с. 2]. Указанная оговорка выглядит, по меньшей мере, не логично, поскольку перечень посреднических услуг, закрепленный в Приложении № 1 к Особым условиям Пурпурной книги, свидетельствует именно об агентской природе этих отношений. Однако для понимания сущности данного «противоречия» следует принимать во внимание, что агентирование по российскому законодательству существенно отличается от 'Agency' - института, существующего в общем праве Англии и Уэльса, а также других стран, чьи правовые системы входят в состав англо-саксонской правовой семьи.

Agency является институтом договорного права, который (если проводить аналогию с нормами российского права, регулирующими сходные отношения) включает в себя институт представительства, институт действий в чужом интеpece без поручения и агентский договор. Полномочия агента делятся на несколько видов: (1) фактические полномочия (actual authority), (2) полномочия, подразумеваемые по обстоятельствам (вытекающие из условий, в которых действует представитель) (apparent authority), (3) полномочия, основанные на последующем одобрении принципалом действий агента (ratification of the Agent's unauthorized acts) [3, c. 1069].

Фактические полномочия (actual authority) разделяются на два подвида: «явно выраженные фактические полномочия» (express actual authority) и «подразумеваемые фактические полномочия» (implied actual authority). Первый подвид характеризуется тем, что полномочия вытекают из условий соглашения между принципалом и агентом; вторые - могут выводиться из конкретных фактических обстоятельств, из условий в которых осуществляется представительство [4, с. 521]. В частности, подразумеваемые фактические полномочия могут быть выведены из: (1) условий соглашения между агентом и принципалом с использованием телеологического толкования (в деле Waugh vs H.B. Clifford \& Sons [1982] суд констатировал наличие полномочий агента, оказывавшего услуги по представительству в суде, заключать обязательные для доверителя соглашения по существу спора, стороной которого является доверитель); (2) должностных обязанностей агента, когда он состоит в трудовых отношения с принципалом (в деле SMC Electronics Ltd vs Akhter Computers Ltd [2001] суд констатировал наличие подразумеваемых фактических полномочий лица, принятого на должность «директора по продажам» и не обладавшего статусом директора компании, опираясь на формулировку в трудовом договоре следующего содержания: «исполнять обязанности, которые могут быть разумно связаны с наименованием должности»); (3) обычая или делового обыкновения, применимого к конкретному случаю (в деле Howard vs Sheward [1866] суд констатировал нали- 
чие полномочия агента выдать гарантию качества на товар, поскольку в силу предоставленных фактических полномочий агент осуществлял продажу такого товаpa) $[4$, с. 521$]$.

Кроме того, институт Agency в общем праве содержит ряд правил, поддерживающих баланс прав и обязанностей сторон, явно не выгодный для принципала, в частности: (1) структура вознаграждения агента, состоит из постоянной оплаты, получаемой за совершение действий по представительству, независимо от положительного результата таких действий, и «комиссии» (commissions) за достижение такого результата (например, заключение договора между принципалом и третьим лицом); (2) обязанность принципала освободить агента от обязательств и ответственности перед третьими лицами (indemnity), возникших вследствие выполнения агентом поручения принципала в соответствии с его явно выраженными инструкциями; (3) ограничение права принципала на расторжение договора с агентом (на данное право принципала влияет подразумеваемое условие договора (implied condition of the contract), обязывающее принципала воздерживаться от действий, препятствующих агенту заработать комиссию за выполнение поручения) [4, с. $538-543]$.

В отличие от правил, указанных выше (существующих в форме прецедентов и доктрин общего права), Общие условия Пурпурной книги предусматривают следующие условия: (1) вознаграждение выплачивается посреднику только в случае достижения положительного результата (например, за заключение договора между консультантом и клиентом) (пдп. 6.3 Общих условий) [2, с. 3];
(2) консультант не несет обязанность по освобождению посредника от обязательств и ответственности перед третьими лицами за действия, предпринятые в ходе оказания посреднических услуг (пдп. 12.1 Общих условий) [2, с. 6]; (3) Соглашение может быть расторгнуто консультантом, путем направления уведомления о нарушении посредником условий Соглашения (п. 9.1 Общих условий), а также может быть прекращено автоматически при наступлении одного из обстоятельств, перечисленных в пдп. 9.2 Общих условий (среди таких обстоятельств названы, например, изменения в составе учредителей или исполнительных органов посредника, нарушение режима защиты конфиденциальной информации) $[2$, с. $4-5]$.

Итак, разработчики Пурпурной книги сочли неприемлемым распространение на отношения сторон правового режима, предусмотренного институтом Общего права 'Agency'. Но, в таком случае, возможно ли применение к регулированию этих договорных отношений норм главы 52 ГК РФ? На этот вопрос следует дать отрицательный ответ. В соответствии с п. 13.1 Общих условий Пурпурной книги, Соглашение регулируется правом страны места нахождения коммерческого предприятия консультанта, осуществляющего деятельность по Соглашению (law of the home base country of the Consultant) [2, с. 6]. В совокупности с условием о подсудности споров арбитражу, который должен действовать в порядке, предусмотренном Регламентом арбитражного суда при Международной торговой палате (п. 13.2, 13.3 Общих условий) отношения, возникающие на основании Соглашения, «изымаются» из сферы действия национального права и юрис- 
дикции страны посредника. Возникает парадоксальная ситуация: агентское по своей природе Соглашение не будет признаваться в качестве такового ни одним из национальных правопорядков, связанных с ним по субъектному составу и месту исполнения. Невозможность применения норм об агентировании к отношениям между консультантом и посредником в части, не урегулированной условиями Соглашения, не будет способствовать эффективности его исполнения (неопределенность правового режима, невозможность восполнения пробелов договорного регулирования и др.).

\section{2. Пурпурная книга как механизм противодействия коррупционным практикам.}

Вторая цель разработки и опубликования Пурпурной книги, заключающаяся в создании механизмов борьбы с коррупционными злоупотреблениями, проявляется практически во всех разделах Соглашения. Многие его условия выработаны под влиянием современной антикоррупционной практики, введенной в оборот международными договорами и национальным законодательством, в частности, Конвенции ООН О борьбе с коррупцией 2004 г. (United Nations Convention against Corruption), британского Акта о противодействии взяточничеству 2010 г. (UK Bribery Act).

Пункт 15 Общих условий Пурпурной книги содержит детальный перечень действий, которые квалифицируются как коррупционные проявления [2, с. 6 - 7]. Практически все действия, поименованные в указанном перечне, представляют собой противоправные деяния, ответственность за которые предусмотрена УК
РФ. Однако этим «антикоррупционный» подтекст Пурпурной книги не исчерпывается. Под его воздействие попали иные условия Соглашения, регулирующие взаимодействие сторон в ходе оказания посреднических услуг.

Например, вознаграждение посредника за оказание услуг подлежит оплате только после того как консультант получит оплату от клиента по договору, заключенному в результате деятельности посредника (т.е. поиска и подбора контрагента, проведения переговоров) (п. 6.3 Общих условий); все расходы, связанные с оказанием услуг, посредник покрывает за свой счет, без отдельной компенсации этих затрат консультантом (п. 6.1 Общих условий); консультант вправе инициировать проведение аудиторских проверок бухгалтерской документации посредника в целях выявления коррупциогенных характеристик в его деятельности (п. 7.1 Общих условий), о выявленных нарушениях аудитор обязан уведомлять консультанта (п. 7.4 Общих условий) [2, с. 3 - 4]. «Антикоррупционной» целью данных условий является исключение возможности подкупа должностных лиц консультантом через посредника; исключение возможности проведения посредником финансовых операций, не связанных с деятельностью консультанта, но способных дискредитировать его. Вместе с тем, очевидно, что данные условия порождают серьезные финансовые и информационные риски для посредника. Под воздействием публичноправового регулирования, осуществляемого в целях противодействия коррупционным практикам, частноправовые условия Соглашения возлагают на посредника дополнительные обязанности и обременения, не характерные 
для традиционной модели агентского договора, как по российскому праву, так и по Общему праву: «договор... не должен возлагать на одну сторону все риски по сделке...» [1, с. 336].

В целом, анализ условий Пурпурной книги свидетельствует об отсутствии принципиальных юридических барьеров, препятствующих применению Соглашения российскими компаниями, желающими оказывать посреднические услуги зарубежным инжиниринговым компаниям и проектировщикам. Следует лишь оценить целесообразность использования данной типовой формы, способной породить неопределенность правового режима отношений, и имеющей явный дисбаланс в распределении рисков между сторонами.

\section{Библиография:}

1. Jaeger A. - V., Hök G. - S. FIDIC - A Guide for Practitioners [Text] / A. - V. Jaeger, G. - S. Hök. - NY: Springer, 2010.

2. FIDIC Model Representative Agreement [Text]: [First edition, 2013]. - Geneva: 2013.

3. Phang A., Yihan G. The Law of Contract in Singapore [Text] / A. Phang, G. Yihan. - Singapore: Academy Publishing, 2012.

4. Poole J. Textbook on Contract Law [Text] / J. Poole-7th edition - NY: Oxford University Press Inc., 2004.

\section{References (transliterated):}

1. Jaeger A. - V., Hök G. - S. FIDIC - A Guide for Practitioners [Text] / A. - V. Jaeger, G. - S. Hök. - NY: Springer, 2010.

2. Phang A., Yihan G. The Law of Contract in Singapore [Text] / A. Phang, G. Yihan. - Singapore: Academy Publishing, 2012.

3. Poole J. Textbook on Contract Law [Text] / J. Poole-7th edition - NY: Oxford University Press Inc., 2004. 